\title{
Health Care Supervisor's Role in Enhancing the Effectiveness of Health Education Areas in Ma' an City Schools in Jordan
}

\author{
Bassam S. Al-Emami ${ }^{1}$ \\ ${ }^{1}$ Jordan Ministry of Health, Jordan \\ Correspondence: Bassam S. Al-Emami, Jordan Ministry of Health, Jordan. E-mail: \\ dr.bassam_Al-Emami@yahoo.com \\ Received: July 20, 2016 \\ doi:10.5539/jel.v6n3p229 \\ Accepted: February 10, 2017 \\ Online Published: April 24, 2017 \\ URL: http://doi.org/10.5539/jel.v6n3p229
}

\begin{abstract}
This study aimed at showing health supervisor's role in enhancing the effectiveness of health education areas in public schools in the city of Ma'an, Jordan, and its relationship to some demographic variables for the academic year 2016-2017.

The study population consists of all health supervisors in public schools in the city of Ma'an for the academic year 2016-2017. The entire school number reached 38 schools including 13 schools for males, and 25 schools for females. The total sample size of the study was 38 supervisors as each school had one health supervisor. Due to the lack of the school populations, all the 38 supervisors had been used by $100 \%$ of the school population for the purpose of this study. In addition, the researcher had used descriptive analytical approach based on the case study or phenomenon as it was existed in the case. This phenomenon had been described accurately and expressed qualitatively and quantitatively.

A study tool of 22 questions had been used for the application of this study and its data collection. The tool included four main parts: the first part contained questions 1-7 related to the first area (nutrition), and the second part contained questions 8-12 of the second area environmental health and public safety, whereas the third part had questions 13-17 which showed the third area the personal health of students and promoting health awareness. As to part four, it contained questions 18-22 related to the fourth area Reproductive health. Each response had been scaled according to Likert Scale Quintet.

Data had been analyzed through the Statistical Package for Social Sciences (SPSS). Also, frequencies, mean as well as standard deviation had been the statistical methods used for describing the variability of some data in our study. Furthermore, differential analysis tests such as analysis of variance test (One-Way ANOVA) had been used to see if there was any difference in the mean scores among groups on some variable. In addition, Cronbach's Alpha had been used to measure the scale consistency.

One of the most important results, shown by our study, had been the significant and effective role of the school health supervisor in Ma'an public schools for the academic year 2016-2017 in all areas of health education mentioned in the questionnaire. In addition, the results showed non-existence of statistically significant differences, attributed to variation in gender and the level of education, at the level of $(\alpha \geq 0.05)$ for the role of health supervisor in enhancing the effectiveness of areas of health education in public schools. In the light of the results obtained in the present study, the researcher made many recommendations, among which the most important are: identifying health officer in each school who must have the required qualifications to hold the title of a health supervisor so that he/she could achieve all responsibilities to the fullest. Another important recommendation was to make an ongoing evaluation of school health programmes in those schools and also make workshops, seminars and conferences for teachers specializing in school health.
\end{abstract}

Keywords: health supervisor, school health, health education, Ma'an city schools

\section{Introduction}

School is one of the most important educational institutions in society due to its educational role which strongly affects the habits and attitudes of students in various physical, mental as well as psychological aspects. The school period lasted approximately twelve years and students spend such period in learning. Therefore, schools became places which support the process of health promotion, provide quality in knowledge, experience and the 
skills essential for the students to maintain growth and development of health and to prepare them to build their community as well (Al-Qahtani \& Tarbush, 2004; Al-Ghunaim \& Al-Behbahani, 1997).

Al-Razihi (2002) indicated that health education is one of the most important issues in the life and community of the students due to its important role that is connected to many life related matters and fields. Health education is also involved in life in a way that makes them difficult to be separated. The life of student is renewed, grown and flourished through the school environment where he/she lives. As such environment becomes disease free and all health and public safety means are available, it produces a competent student that serves his/her country and builds its future.

Due to the significance of health education fields in general to many different students and all age groups in growth and good health, many studies focused on those fields in various levels of education, including: Marzouq (2013) showed the impact of specialized courses of nutrition on the education of secondary students. This study concluded that such courses have their influence on those students in improving their health and increasing their basic skills and experiences related to nutrition. This means that these courses were taught properly and, therefore, care must be taken by those in charge of curriculum planning in order to determine food topics intended for both male and female students and complement these courses with food concepts that help to develop the students' abilities and their habits as well.

Additionally, as students have good eating habits and health behavior, their health will be improved and their academic achievement will be increased. He recommended the need to emphasize the development of those habits, and to add new food concepts to the education curriculum, especially for the basic and university education (Al-Mohjah, 2009).

This is what Barwa et al. (2000) confirmed on their study about educating adolescent students to nutrition habits. These students have to find positive relation between what is learnt and their priorities of selecting the right healthy food at the levels of home, school and external environment. They also emphasized the importance of educational campaigns related to food and nutrition concentration on school with this respect.

Furthermore, school health services became an important issue and a priority that must be followed and they were investment for the future and effective special tool for improving community health (Abu Laila, 2002). Badah (2006) and Al-Mejber (2004) aimed at recognizing the health services for students at schools, their availability as well as their influence on the health of students. The study concluded that whenever such health services are viable and available for the students, their health and food are safe and they are disease free as well.

We note that the study of (Contento et al., 2007) focused on the impact of the practical application of students through the school curriculum, and the idea of promoting the trends toward healthy eating, doing activities and reaching appropriate and healthy weight. This study found the most important results by improving the performance of students' school achievement, their interest in physical activities as well as eating fruits and vegetables. One thing to notice here is that as long as there is an application of the school curriculum in real life, students will be more beneficial and their healthy trends and habits will be developed properly.

Therefore, we found that the students whose school age is up to 18 years represent about one third of the population. Also, this age period was featured by its growth and rapid development in all aspects, and the acquisition of healthy behavior which affects both the family and society, and that students in this age group were more vulnerable to infectious diseases, because of congestion inside the classroom, differences in social levels, health and personal hygiene, so educational guidance personnel and executives must be available to develop and deliver health services and programs in schools, for better health of the students (Khudair, 2001).

Moreover, in a study conducted by Al-Otaibi (2011) an educational software was used to improve the performance of students and their academic achievement through levels of awareness which led to positive results in improving the health of the students and their performance and academic achievement.

Kahan and Leiden et al. (2014) detected the availability of nutritional practices, healthy activity among female adolescents in a rural area. This study confirmed the provision of school food programs that improve students' behavior through appetite for healthy food, and focus on the breakfast, which is considered one of the most important meals. It also encourages doing the most important exercises such as jogging.

Here comes the role of school health official on top of the situation to provide health services at school, improve and promote health behaviour of the students, react with them and behave them, and to have them show their expertise, and do the best to provide them with healthy eating habits and concepts, that make their integrated and comprehensive growth in all aspects of life (Ahmad, 2005). 


\section{Study Problem}

The problem of our study came from the importance of health education which is considered an important topic in the school health field. Attention to the areas of school health education as well as their application have an important role in achieving the important goal sought by all schools in Jordan. Therefore, the Education Act confirms its interest in health and health awareness, through a number of its articles on the importance of grasping the hygiene rules and exercise related habits (The Prime Minister's office of Jordan, 2003).

Consequently, school health supervisors must seek a healthy and suitable environment which enables the school to achieve its objectives in enhancing and promoting students by raising awareness in health and nutrition, changing their wrong behaviors, and developing good health habits.

This study showed the role of school health supervisor in Ma'an public schools and its relationship to some demographic variables for the academic year 2016-2017.

\section{Study Objectives}

1) To show health supervisor's role in enhancing the effectiveness health education areas in public schools in the city of Ma'an, Jordan, and its relationship to some demographic variables for the academic year 2016-2017.

2) To show ways (methods) that enable health supervisor to activate areas of health education in Ma'an public schools in the light of the study results for the academic year 2016-2017.

\section{Importance of the Study}

1) The importance of that study was highlighted through a matter of great importance, which the school health supervisor was doing in providing health services and their follow-up and then identifying those services and the problems he/she faced at school, and to propose appropriate solutions for each problem, which results in achieving some desired educational goals in pursuit of integrated and balanced growth in all physical, mental, emotional and social aspects.

2) The study was a response to the great development of the education sector in Jordan. This suggested the possibility of employing its results to reinvigorate development and activate a broader and more comprehensive health education in those schools.

3) To look into the views and ideas of school health supervisors regarding various areas of health education, the extent to which their school health services had developed, their future outlook as well as their awareness and thinking to develop their present real life.

4) To emphasize the functional relationship between the various methods of education and the needs of our students to those health services in addition to their role to make a healthy, safe generation having an awareness to the roles in building society.

\section{Study Questions}

Q1: What is the role of supervisor (health officer) in enhancing the effectiveness of health education areas through the four areas (nutrition, environmental health, health and personal health awareness, and reproductive health) in Ma'an city public schools for the academic year 2016-2017?

Q2: Are there statistically significant differences, attributed to variation in gender, years of experience, education and specialization, at the significance level of $(\alpha \geq 0.05)$ for the role of health supervisor for the academic year 2016-2017? This question can, accordingly, be divided into four different areas.

Q3: What are the main ways that can contribute to the activation of health education areas from the perspective of the school health supervisor for the academic year 2016-2017?

\section{Study Hypotheses}

1) Non-existence of statistically significant differences at the level of $(\alpha \geq 0.05)$ for the role of health supervisor in enhancing the effectiveness health education areas in four areas in Ma'an city public schools.

2) Non-existence of statistically significant differences, attributed to variation in gender, years of experience, education and specialization, at the level of $(\alpha \geq 0.05)$ for the role of health supervisor in enhancing the effectiveness health education areas in Ma'an public schools? 


\section{Limitations of the Study}

Place: all Ma'an city government schools.

Time: this study had been applied for the current academic year (2016-2017).

Quality: this study was restricted to all health supervisors in all Ma'an public schools.

\subsection{Study Terms}

Health supervisor: a member of the teaching staff who are placed by the principal and had the job title of school health supervisor in order to do all school health services planned by the Ministry of Education, and provide the entire services in collaboration with the staff of the Ministry of Health.

Health education: a full range of individual's educational experiences which have a positive impact on his/her information, habits and trends related to his/her health and the community health (Wood, 1987).

Ma'an city public schools: all the 38 males and females government schools of Ma'an.

\subsubsection{Study Approach}

The nature and pre-set objectives of the current study imposed using descriptive analytical approach based on the case study or phenomenon as it exists in reality and described it accurately and expressed it qualitatively and quantitatively (Adas, 1999).

\subsubsection{Study Population}

Study population consisted of all public schools in the city of Ma'an for the academic year 2016-2017. The entire school number reached 38 schools including 13 schools for males, and 25 schools for females. The number of schools and their distribution has been undertaken by the Department of Statistics and Planning at the Directorate of Education in the city of Ma'an.

\subsubsection{Study Sample}

The total sample size of study was 38 health supervisors. Due to lack of the school community, all the 38 supervisors had been used by $100 \%$ of the school community.

\subsubsection{Study Tool}

In light of the nature and dimensions of study problem and its primary goal, a questionnaire had been created to detect the school health supervisor role in enhancing the effectiveness the areas of health education in Ma'an city public schools for the school year 2016-2017.

A. Sources of building-study tool

The researcher adopted the following sources to build study tool:

- Primary sources: Study tool (questionnaire) had been designed to gather the primary data.

- Secondary sources: the researcher had used books, periodicals, journals, previous studies and websites to be able to build a theoretical framework and achieve theoretical goals.

B. A description of the initial study tool

In light of the above, the main areas of study tool, which include the following two main areas, had been selected:

The first area: included the demographic data for study sample.

The second area: this part included a set of paragraphs with specific question for each one.

1-22 to include the four parts below:

1) The first part includes questions (1-7) which refer to the first area (Nutrition).

2) The second part includes questions (8-12) which refer to the second area (Environmental Health and Public Safety).

3) The third part contains questions (13-17) which show the third area (Students' Personal Health and promoting Health Awareness).

4) The fourth part includes questions (18-22) that refer to the fourth area (Reproductive Health). 
Responses for each question had been scaled according to Likert Scale Quintet. A choice of five responses had been set out such as always, often, sometimes, rarely, never. Additionally, the degrees of study tool had been represented as $1,2,3,4,5$, respectively.

C. A description of finalized study tool:

The tool had included the several main areas below:

- Introduction: this addresses school health supervisors and showed the purpose of the study, response instructions and requirements of accuracy and objectivity.

- Health supervisor data: which was the information related to health supervisor such as education, gender, years of experience and specialization.

- The tool had included the four areas: nutrition, environment and public safety, personal health and promoting health awareness and reproductive health.

\subsection{Reliability of the Study Tool}

After the initial setting up of the tool to make it appropriate to the purpose for which it had been planned and more realistic and relevant to the nature of the study, we found out the following:

A. The extent to which the tool items were appropriate in terms of language and scientific accuracy.

B. The tool suitability to achieve the goal for which it had been set.

C. Question indication to the intended meaning.

D. Each question belongs to its domain.

Therefore, I must follow the apparent reliability of the tool by showing it to a group of six experienced and specialized arbitrators who are members of the teaching staff at the Jordanian universities.

The most important notes, which made by the arbitrators, on the tool had been summarized in the following points:

- to delete some items because of replication, having an alternative or being unnecessary.

- to rework some items because they were composed in order to make each item include only one idea or summarize the other ones.

- to add some items, and rearrange some others.

- to keep items which the majority of arbitrators agreed upon, and cancel items with different views on their importance.

Following the above amendments, according to the arbitrators' opinions and suggestions which had a good impact, the tool items had been finalized.

\subsection{Consistency of the Study Tool}

It had been confirmed that the study tool was consistent so as to be applied to an exploratory sample of seven health supervisors from outside the study community before starting the application of study on the selected sample. The tool consistency had been calculated by Cronbach's alpha because it was the best and most common way to measure consistency estimation.

The tool consistency value had reached $80.05 \%$ as a group.

For example:

Table 1. Consistency values of the tool areas

\begin{tabular}{cccc}
\hline Tool Consistency Value as a group & ALPHA Consistency Value & Questions & Tool \\
\hline $80.05 \%$ & $81.2 \%$ & $(1-7)$ & Nutrition \\
& $78.5 \%$ & $(8-12)$ & Environmental Health and Public Safety \\
& $79.9 \%$ & $(13-17)$ & Personal Health \\
& $80.6 \%$ & $(18-22)$ & Reproductive Health \\
\hline
\end{tabular}


The above values illustrate the good percentage of tool consistency or indicate that the scale is at a very good degree. Consequently, the scale is useful to be used and applied (Malhotra, 2004).

\subsubsection{Application of Study Tool}

After finalizing the study tool, a letter, to the principals of Ma'an city, was received from Ma'an director of education to facilitate the task of the researcher. The tool had been distributed to all public schools during the second semester of the academic year 2016-2017. The total number of questionnaires distributed had reached 38 questionnaires which had been distributed to all school community and retrieved by 100 percent. Distribution and collection of questionnaires, done by the researcher, had taken two weeks.

\subsubsection{Statistical Methods}

After collecting and reviewing the questionnaires, the professors specialized in statistics were consulted to determine the appropriate statistical methods. Statistical Package for the Social Sciences (SPSS) had been used as directed by them for statistical data analysis as follows:

1) Descriptive statistics: frequencies, mean and standard deviation for describing the study variables.

2) Differential analysis tests such as analysis of variance test (One Way ANOVA) had been used in other hypotheses testing. Such analysis had been used to see if there were moral differences among mean values of groups and their relation to the dependent variable.

\subsubsection{Features of Study Sample}

Frequencies and percentage of information regarding demographic factors of the school community had been calculated. Responses can be summarized in the Tables (1-2) below:

Table 2. Study sample according to gender

\begin{tabular}{cccc}
\hline Variation & Categories & Frequencies & Percentage (\%) \\
\hline \multirow{3}{*}{ Gender } & Male & 15 & 39.5 \\
& Female & 23 & 60.5 \\
& Total & $\mathbf{3 8}$ & $\mathbf{1 0 0 \%}$ \\
\hline
\end{tabular}

\subsubsection{Gender}

Data in the Tables (1-2) above, which is about distribution of study sample according to gender, shows that $39.5 \%$ of the total study sample size were males while $60.5 \%$ were females.

Table 3. Study sample according to experience

\begin{tabular}{cccc}
\hline Variation & Categories & Frequencies & Percentage (\%) \\
\hline \multirow{2}{*}{ Experience } & Less than 5 years & 10 & 26.4 \\
& $10-5$ years & 14 & 38.8 \\
& More than 10 years & 14 & 38.8 \\
\hline
\end{tabular}

Data in the Tables (1-3) above, which is about distribution of study sample according to years of experience, shows that the highest percentage of experience for 5-10 years and for more than 10 years had reached 38.8\% followed by experience for less than 5 years which had reached 26.4. This indicates that the majority of study sample had been for 5-10 years of experience and more. 
Table 4. Study sample according to education

\begin{tabular}{cccc}
\hline Variation & Categories & Frequencies & Percentage (\%) \\
\hline \multirow{2}{*}{ Education Level } & Diploma & 1 & 2.6 \\
& Bachelor & 28 & 73.7 \\
& Master & 9 & 23.7 \\
& Total & $\mathbf{3 8}$ & $\mathbf{1 0 0 \%}$ \\
\hline
\end{tabular}

Data in the Tables (1-4) above, which is about distribution of study sample according to education level, shows that the highest percentage of the total study sample had reached $73.7 \%$ for Bachelors degree holders whereas the percentage of Master's degree holders had reached 23.7\%. As for Diploma holders, it had been $2.6 \%$ of the total searched sample.

Table 5. Study sample according to specialization

\begin{tabular}{cccc}
\hline Variation & Categories & Frequencies & Percentage (\%) \\
\hline \multirow{3}{*}{ Specialization } & Specialized & 16 & 42.1 \\
& Unspecialized & 22 & 57.9 \\
& Total & $\mathbf{3 8}$ & $\mathbf{1 0 0 \%}$ \\
\hline
\end{tabular}

\subsubsection{Specialization}

Data in the Tables (1-5) above, which is about distribution of study sample according to specialization, shows that $42.1 \%$ of the total study sample were specialized in health related matters whereas the percentage of unspecialized individuals had reached $57.9 \%$ which is the highest one indicating they had nothing to do with the title of school health supervisor such as teachers of Arabic, history, English, etc.

\section{Analysis of Hypotheses}

\subsection{Results of Study Hypotheses Testing}

1) There were no statistically differences at the significance level $(\alpha \geq 0.05)$ for the role of health supervisor in enhancing the effectiveness health education areas in four areas in Ma'an city public schools.

2) There were no statistically differences, attributed to variation in gender, years of experience, education and specialization, at the significance level $(\alpha \geq 0.05)$ for the role of health supervisor in enhancing the effectiveness health education areas in Ma'an public schools.

\subsubsection{Hypothesis 1}

There were no statistically differences at the significance level $(\alpha \geq 0.05)$ for the role of health supervisor in enhancing the effectiveness health education areas in four areas in Ma'an city public schools.

Table 6. Mean and standard deviation values for nutrition

\begin{tabular}{|c|c|c|c|}
\hline Standard Deviation & Mean & Phrase & No. \\
\hline 1.08 & 4.26 & To encourage students to have breakfast. & 1 \\
\hline, 83 & 4.45 & $\begin{array}{l}\text { To raise students awareness of the importance of having fruits } \\
\text { and vegetables daily. }\end{array}$ & 2 \\
\hline ,99 & 4.21 & To apply the healthy conditions at the school cafeteria. & 3 \\
\hline 1.04 & 3.31 & $\begin{array}{l}\text { To held periodic informative lectures for the health of children } \\
\text { and their food. }\end{array}$ & 4 \\
\hline 1.07 & 3.24 & $\begin{array}{l}\text { To prepare educational brochures about nutrition education for } \\
\text { the students. }\end{array}$ & 5 \\
\hline
\end{tabular}




\begin{tabular}{llll}
\hline $\mathbf{1 . 1 6}$ & $\mathbf{3 . 8 2}$ & $\begin{array}{l}\text { To encourage students to present food and nutrition related } \\
\text { topics by taking part in the school radio activities. }\end{array}$ & 6 \\
$\mathbf{1 . 0 6}$ & $\mathbf{2 . 8 2}$ & $\begin{array}{l}\text { To make sure to supply the school library with nutrition books } \\
\text { for all age groups. }\end{array}$ & 7 \\
$\mathbf{1 . 0 3}$ & $\mathbf{3 . 7 3}$ & General average \\
\hline
\end{tabular}

Nutrition variable had been shown according to responses of study sample to questions 1-7 based on mean value of 38 responses. The final mean value 3.73 was higher than mean of study measuring tool and was lying between the degree of neutrality +3 and the agreement degree +4 .

Responses of study sample ranged from 4.45 , to question no. 2, which was the highest mean value to 2.82 , to question no. 7, which was the lowest. Question no. 2 was about raising the students awareness to the importance of having fruits and vegetables daily whereas question no. 7 was about making sure to supply the school library with nutrition books for all age groups. This shows how much school health supervisors care about healthy nutrition of students while being in schools. Regarding responses to question no. 7. Teachers show a weak side because Ma'an directorate of education is responsible for providing nutrition book in schools.

Table 7. Mean and standard deviation values for environmental health and public safety

\begin{tabular}{|c|c|c|c|}
\hline Standard Deviation & Mean & Phrase & No. \\
\hline 0.58 & 4.63 & $\begin{array}{l}\text { To take into account all health and environment requirements of the school } \\
\text { building (lighting, ventilation, etc.). }\end{array}$ & 8 \\
\hline 0.97 & 4.38 & $\begin{array}{l}\text { To make sure that my school is provided with health and public safety } \\
\text { devices and tools such as first-aid kit, fire extinguisher, etc. }\end{array}$ & 9 \\
\hline 0.99 & 4.34 & $\begin{array}{l}\text { To ensure that drinking water is safe and test it in collaboration with the } \\
\text { competent authorities. } \\
\text { (The Ministry of Health) }\end{array}$ & 10 \\
\hline 1.02 & 3.84 & $\begin{array}{l}\text { To train students on a school evacuation plan in case of accidents and } \\
\text { disasters. }\end{array}$ & 11 \\
\hline 0.57 & 4.68 & $\begin{array}{l}\text { To take care of permanent hygiene of the health utilities in schools such as } \\
\text { drinking water faucets and toilets. }\end{array}$ & 12 \\
\hline 0.83 & 4.37 & General average & \\
\hline
\end{tabular}

Variable of public safety and environmental health has been shown according to responses of study sample to questions 8-12 based on mean value of 38 responses. The final mean value 4.37 was higher than mean of study measuring tool and was lying between the degree of neutrality $4+$ and the agreement degree $5+$.

Responses of study sample ranged from 4.68 , to question no. 12 , which was the highest mean value to 3.84 , to question no. 11, which was the lowest. Question no. 12 was about taking care of permanent hygiene of the health utilities in schools such as drinking water faucets and toilets whereas question no. 7 was about training students on a school evacuation plan in case of accidents and disasters.

This shows how good school health supervisors in having health awareness as well as showing constant interest in health facilities because these facilities represent a serious source of disease transmission to the students, while question with the lowest response rate indicates a clear negligence of the school health supervisors maybe because the area had not accidents or natural disasters. Other reasons may include so much time and effort required for learning, as well as large numbers of students within each school, leading to wasting class time and confusing students and teachers. 
Table 8. Mean and standard deviation values for students personal health and promotion of health awareness

\begin{tabular}{lll}
\hline Standard Deviation & Mean & Phrase \\
\hline 1.09 & 3.78 & $\begin{array}{l}\text { To train students on how to deal with household wastes } \\
\text { and sort them properly. }\end{array}$ \\
1.03 & 3.60 & $\begin{array}{l}\text { To do meaningful environmental health journeys. } \\
\text { To raise students awareness of the importance of exercise } \\
\text { to the human health. }\end{array}$ \\
1.81 & 3.66 & $\begin{array}{l}\text { To give educational lectures on first-aid training. } \\
\text { To encourage students to do the preliminary and } \\
\text { periodical medical tests continuously. }\end{array}$ \\
\hline
\end{tabular}

Variable of students' personal health and promotion of health awareness has been shown according to responses of study sample to questions 13-17 based on mean value of 38 responses. The final mean value 3.75 was higher than mean of study measuring tool for this study and lies between the degree of neutrality +3 and the agreement degree +4 .

Responses of study sample ranged from 4.31 , to question no. 15 , which was the highest mean value to 3.42 , to question no. 17, which was the lowest. Question no. 15 was about raising students' awareness of the importance of exercise to the human health while question no. 17 was about encouraging students to do the preliminary and periodical medical tests continuously.

This indicates that health supervisors have the knowledge doing exercises continuously makes the students very healthy and avoid some non communicable diseases such as obesity and other sicknesses. Constant exercises are also related to the academic performance. As students become healthy and disease free, their academic achievement is better (Al-Abbad Hussain, 2008). And as for question (no. 17) with the lowest responses rate. Health supervisors believe that this matter is an obligation of Ma'an city doctors who have no role other than guidance and counselling.

Table 9. Mean and standard deviation values for reproductive health

\begin{tabular}{|c|c|c|c|}
\hline Standard Deviation & Mean & Phrase & No. \\
\hline 1.26 & 2.44 & To raise students awareness of the dangers of early marriage. & 18 \\
\hline 1.25 & 2.71 & $\begin{array}{l}\text { To make sure that the information which students get about } \\
\text { reproductive health coming from reliable sources such as } \\
\text { relevant books, documentaries, lectures, etc. }\end{array}$ & 19 \\
\hline 1.45 & 3.34 & $\begin{array}{l}\text { To raise students awareness about transmission methods of } \\
\text { communicable and non-communicable diseases. }\end{array}$ & 20 \\
\hline 1.26 & 2.73 & $\begin{array}{l}\text { To host doctors from the Ministry of Health to talk about } \\
\text { reproductive health related topics. }\end{array}$ & 21 \\
\hline 1.42 & 2.68 & To educate students the safe reproductive health practices. & 22 \\
\hline 1.33 & 2.78 & General Average & \\
\hline
\end{tabular}

Reproductive health variable has been shown according to responses of study sample to questions 18-22 based on mean value of 38 responses. The final mean value 2.78 was lower than the mean of study measuring tool for this study.

Responses of study sample ranged from 3.34 , to question no. 20, which was the highest mean value, to 2.44 , to question no. 18, which was the lowest. Question no. 20 was about raising students' awareness about transmission methods of communicable and non-communicable diseases, whereas question no. 18 was about raising students' awareness of the dangers of early marriage. 
This refers to how much interest health supervisors show for the students' health and raising their awareness of the communicable diseases, their transmission methods and reasons to ensure a disease-free generation.

As mentioned above, "Raising students' awareness of the dangers of early marriage" was of the lowest responses. Therefore, most schools ( 31 schools) are basic schools with students less than 13 years old. Consequently, there is no awareness of the dangers of early marriage. Moreover, some teachers neither have the least knowledge nor the suitable specialization in reproductive health in order to be able to raise awareness and provide guidance, so they have weakness in this aspect.

To prove hypothesis, the mean values of the four areas below have been calculated as follows:

- The mean value of nutrition is 3.73 .

- The mean value of environmental health is 4.37 .

- The mean value of personal health is 3.75 .

- The mean value of reproductive health is 2.78 .

- The mean value of all above areas is 3.65 which is higher than the mean value of the measuring tool for this study and lies between the degree of neutrality $(+3)$ and the agreement degree $(+4)$. This shows the role of health supervisor in government schools of Ma'an city on all four areas. Therefore, null hypothesis, the hypothesis that there is no statistically significance difference for the role of health supervisor in enhancing the effectiveness health education areas in Ma'an city public schools, is rejected.

\subsubsection{Hypothesis 2}

Results of the one-way analysis of variance (ANOVA) test for the role of health supervisor in enhancing the effectiveness areas of health education in Ma'an city public schools according to sex.

Table 10. Test for the role of health supervisor in enhancing the effectiveness areas of health education in Ma'an city public schools according to sex

\begin{tabular}{|c|c|c|c|c|c|}
\hline Field & Sources of variation & Sum of Squares & $\begin{array}{c}\text { Degrees of } \\
\text { Freedom }\end{array}$ & F variable & Siq. \\
\hline & Between groups & 0.129 & 2.408 & & \\
\hline \multirow[t]{3}{*}{ Nutrition } & Within groups & 38 & 17.131 & 1 & 1.146 \\
\hline & Total & 37 & 18.277 & & \\
\hline & Between groups & 0.478 & 0.514 & & \\
\hline \multirow[t]{3}{*}{$\begin{array}{c}\text { Environmenta } \\
\text { Health }\end{array}$} & Within groups & 38 & 16.003 & 1 & 0.229 \\
\hline & Total & 37 & 16.232 & & \\
\hline & Between groups & 0.547 & 0.370 & & \\
\hline \multirow{2}{*}{$\begin{array}{c}\text { Personal } \\
\text { Health }\end{array}$} & Within groups & 38 & 13.348 & 1 & 0.583 \\
\hline & Total & 37 & 13.485 & & \\
\hline \multirow{3}{*}{$\begin{array}{c}\text { Reproductive } \\
\text { Health }\end{array}$} & Between groups & 0.782 & 0.078 & & \\
\hline & Within groups & 38 & 48.48 & 1 & 0.104 \\
\hline & Total & 37 & 48.592 & & \\
\hline
\end{tabular}


The results above show no statistically significance level 0.05 at all areas of nutrition, environmental health, personal health and reproductive health. Siq value was higher than 0.05 according to sex. Null hypothesis indicates that there is no statistically significance difference for the role of health supervisor in enhancing the effectiveness health education areas in Ma'an city public schools attributed to variation in sex. This is because all male and female teachers receive the same information, knowledge and training and, consequently, they accomplish all their required works at the fullest.

\subsubsection{Hypothesis 3}

Results of the one-way analysis of variance (ANOVA) test for the role of health supervisor in enhancing the effectiveness areas of health education in Ma'an city public schools according to years of experience.

Table 11. The role of health supervisor in enhancing the effectiveness areas of health education in Ma'an city public schools according to years of experience

\begin{tabular}{|c|c|c|c|c|c|}
\hline Field & Sources of variation & Sum of Squares & $\begin{array}{c}\text { Degrees of } \\
\text { Freedom }\end{array}$ & F variable & Siq. \\
\hline \multirow{3}{*}{ Nutrition } & Between groups & 0.580 & 0.554 & \multirow{3}{*}{2} & \multirow{3}{*}{0.561} \\
\hline & Within groups & 35 & 17.717 & & \\
\hline & Total & 37 & 18.277 & & \\
\hline \multirow{3}{*}{$\begin{array}{c}\text { Environmental } \\
\text { Health }\end{array}$} & Between groups & 0.949 & 0.053 & \multirow{3}{*}{2} & \multirow{3}{*}{0.049} \\
\hline & Within groups & 35 & 16.183 & & \\
\hline & Total & 37 & 16.232 & & \\
\hline \multirow{3}{*}{$\begin{array}{c}\text { Personal } \\
\text { Health }\end{array}$} & Between groups & 0.037 & 0.964 & \multirow{3}{*}{2} & \multirow{3}{*}{0.028} \\
\hline & Within groups & 35 & 13.457 & & \\
\hline & Total & 37 & 13.485 & & \\
\hline \multirow{3}{*}{ Reproductive } & Between groups & 1.296 & 0.286 & \multirow{3}{*}{2} & \multirow{3}{*}{3.351} \\
\hline & Within groups & 35 & 45.241 & & \\
\hline & Total & 37 & 48.592 & & \\
\hline
\end{tabular}

The results above show no statistically significance level 0.05 at areas of nutrition and reproductive health as Siq value was higher than 0.05 according to experience.

Concerning environmental health and personal health, there is a statistically significance level. This is because the majority of school health supervisors do not have the required knowledge, training and experience at all areas. Additionally, some specializations of teachers have nothing to do with health matters which, in turn, lead to general weakness of some areas for the teacher whereas the two areas of environmental health and personal health have criteria and requirements that should be focused on in the long term.

\subsubsection{Hypothesis 4}

Results of the one-way analysis of variance (ANOVA) test for the role of health supervisor in enhancing the effectiveness areas of health education in Ma'an city public schools according to education. 
Table 12. The role of health supervisor in enhancing the effectiveness areas of health education in Ma'an city public schools according to education

\begin{tabular}{|c|c|c|c|c|c|}
\hline Field & Sources of variation & Sum of Squares & $\begin{array}{l}\text { Degrees of } \\
\text { Freedom }\end{array}$ & F variable & Siq. \\
\hline & Between groups & 0.061 & 3.034 & & \\
\hline \multirow{3}{*}{ Nutrition } & Within groups & 35 & 15.577 & 2 & 2.700 \\
\hline & Total & 37 & 18.277 & & \\
\hline & Between groups & 0.566 & 0.573 & & \\
\hline Environmental & Within groups & 35 & 15.723 & 2 & 0.509 \\
\hline & Total & 37 & 16.232 & & \\
\hline \multirow{3}{*}{$\begin{array}{c}\text { Personal } \\
\text { Health }\end{array}$} & Between groups & 0.271 & 1.354 & & \\
\hline & Within groups & 35 & 12.517 & 2 & 0.968 \\
\hline & Total & 37 & 13.485 & & \\
\hline \multirow{3}{*}{$\begin{array}{c}\text { Reproductive } \\
\text { Health }\end{array}$} & Between groups & 0.118 & 2.272 & & \\
\hline & Within groups & 35 & 43.009 & 2 & 5.583 \\
\hline & Total & 37 & 48.592 & & \\
\hline
\end{tabular}

The results above show no statistically significance level 0.05 at all areas of nutrition, environmental health, personal health and reproductive health. Siq level was higher than 0.05 then the null hypothesis, which indicates that there is no statistically significance difference for the role of health supervisor in enhancing the effectiveness health education areas in Ma'an city public schools attributed to variation in education, was accepted because anyone who is assigned to be a school health supervisor receives all information, knowledge, responsibilities and duties regardless of his/her education.

\subsubsection{Hypothesis 5}

Results of the one-way analysis of variance (ANOVA) test for the role of health supervisor in enhancing the effectiveness areas of health education in Ma'an city public schools according to specialization.

Table 13. The role of health supervisor in enhancing the effectiveness areas of health education in Ma'an city public schools according to specialization

\begin{tabular}{|c|c|c|c|c|c|}
\hline Field & Sources of variation & Sum of Squares & Degrees of Freedom & F variable & Siq. \\
\hline \multirow{3}{*}{ Nutrition } & Between groups & 0.057 & 3.852 & \multirow{3}{*}{1} & \multirow{3}{*}{1.76} \\
\hline & Within groups & 38 & 16.511 & & \\
\hline & Total & 37 & 18.277 & & \\
\hline \multirow{3}{*}{$\begin{array}{c}\text { Environment } \\
\text { Health }\end{array}$} & Between groups & 0.174 & 1.926 & \multirow{3}{*}{1} & \multirow{3}{*}{0.824} \\
\hline & Within groups & 38 & 15.408 & & \\
\hline & Total & 37 & 16.232 & & \\
\hline
\end{tabular}




\begin{tabular}{ccccc}
\hline & Between groups & 0.210 & 1.626 & \\
Personal & Within groups & 38 & 12.902 & 1 \\
Health & Total & 37 & 13.485 & 0.583 \\
& Between groups & 0.035 & 1.400 & 1 \\
Reproductive & Within groups & 38 & 46.773 & 0.244 \\
Health & Total & 37 & 48.592 & \\
\hline
\end{tabular}

The results above show no statistically significance at the 0.05 level at areas of nutrition, environmental health and personal health as Siq level was higher than 0.05 while there is a statistically significance at reproductive health area as Siq level was less than 0.05 according to specialization. This is because some school health supervisors have specializations which are completely different from the specialization required to occupy the job of health supervisor in school such as management, Arabic or Islamic education, etc. Consequently, their health related aspect of reproductive health is very weak.

Q3: What are the main ways that can contribute to enhance the effectiveness of health education from the perspective of the school health supervisor?

1) Hosting doctors from the Ministry of Health and the General Directorate of Health Affairs in the province to raise students' awareness and provide guidance on their health related matters, problems they may face and diseases which may be transmitted during their studies.

2) Encouraging teachers, especially unqualified ones in health education, to take part in seminars and workshops on health education of all fields without exception.

3) Continuous Communication between the school and the family and implementing education peogrammes on health for families of the students as well as motivating them to take care of their sons and daughters.

4) Drawings in the school buildings and on the outer walls to encourage the students to engage in health good practices.

5) Enhancing the effective role of the school radio due to its major and effective role in guidance and learning in addition to the role of the school cafeteria by the direct obligation of health requirements.

6) Establishing health committees by some specialized teachers and students in order to raise health awareness in school.

\section{Conclusions}

As has been noted, school health supervisors have a major effective role in Ma'an city public schools for the academic year 2016-2017 in all areas of health education mentioned in the questionnaire. No existence of statistically significant differences has been found at the $\alpha \geq 0.05$ level for the role of health supervisor in enhancing the effectiveness of health education areas in Ma'an city public school according to variations in sex and education level specialization except for reproductive health area.

As to variation in years of experience, no existence of statistically significant differences has been found at the $\alpha$ $\geq 0.05$ level with the exception of personal and environmental health areas. Furthermore, there has been no existence of significant differences at the $\alpha \geq 0.05$ level according to variation in specialization except in reproductive health area.

\section{Recommendations}

1) To identify health officer in each school whose specialty meets the requirements to hold the title of a health supervisor and enables him/her to do all responsibilities to the fullest.

2) To make an ongoing evaluation of school health programmes in those schools and identify weak points to get them over and look at strong points to promote them.

3) To establish cooperation between the Ministry of Health and the Ministry of Education to have workshops, seminars and conferences for teachers specializing in school health. 
4) To continuously focus on reproductive health related aspects in schools by doctors of the Ministry of Health and teachers.

5) To undertake further health related studies that take care of the health of students and their families.

\section{References}

Abu-Laila, A. (2002). School health and Health care (1st ed.). Al-Manahej office for publishing and distributing, Amman.

Adas, A. (1999). Principles of educational research (3rd ed., p. 101). Al-Fourqan House of Publishing, Amman.

Ahmad, T. M. (n.d.). The Impact of Teaching Proposed Nutrition Awareness Programme at the Nutrition Unit on the achievement of Secondary First Grade Female Pupils in Makkah City Schools (pp. 70-71). Umm al-Qura University, Mekkah.

Al-Abbad, N. A., \& Hussein, S. M. (2008). Food Intake and its Relation to the Academic Achievement and Intelligence of King Faisal University Female Students in Al-Ahsa Governorate (pp. 5-43). College of Food and Agriculture Sciences Research Centre, King Saud University.

Al-Ghunaim, M. Y., \& Al-Behbehani, B. I. (1997). Health Culture (3rd ed., p. 376). Dar Al-salasel, Kuwait.

Al-Otaibi, A. (2011). The Effectiveness of Using Proposed Food Educational Software in Teaching Elementary First Grade Female Pupils in Makkah City, College of Education Curricula and Home Economics Departments, Umm Al-Qura University K Mekkah.

Al-Qahtani, H. A., \& Tarboush, H. (2004). A variety of local delicious school meals (p. 34). Aalm Aalgedha waldawa.

Contento, I. R., Koch, P. A., Lee, H., Sauberli, W., \& Calabrese-Barton, A. (2007). Enhancing personal Agency and competence in Eating and Moving: Formative Evaluation of a Middle School Curriculum-choice, Control, and Change. Journal of Nutrition Education and Behavior, 39(5), 79-86. https://doi.org/10.1016/j.jneb.2007.02.006

Department of Jordan Prime Minister. (2010). A collection of the Laws, Regulations and Public Educational Instructions. The Ministry of Education, Amman.

Kahn, K., Edin, K., Gitau, T., Ivarsson, A., \& Norris, S. A. (2014). Qualitative study exploring healthy eating practices and physical activity among adolescent girls in rural South Africa (Vol. 14, No. 1, p. 211). University of Witwatersrand, Johannesburg, South Africa, BMC Pediatr.

Khudair, M. T. (2001). Principles of health and public safety (1st ed., pp. 40-41). Al-Safa house for publishing and istributing, Amman.

Malhotra, N. K. (2004). Marketing research (4th ed., p. 268). Prentice Hall, New Jersey.

Marzouq, E. (2013). The Effect of Specialized Courses of Nutrition to Secondary Students of Hotel Management on Their Nutrition Information in Port Said. Faculty of Specific Education, Department of Home Economics, Port Said University, Egypt.

Nabag, F., \& Dafalla, O. A. (n.d.). Assessment of the Nutritional and Health Status of Basic School Children in Khartoum State. In Journal of Science and Culture (3th ed., Vol. 10, pp. 139-159). Faculty of Agriculture, Sudan University of Science and Technology.

Thomas, W. (1987). Health Education (3rd ed.). New York.

\section{Copyrights}

Copyright for this article is retained by the author(s), with first publication rights granted to the journal.

This is an open-access article distributed under the terms and conditions of the Creative Commons Attribution license (http://creativecommons.org/licenses/by/4.0/). 